\title{
Characteristics of Maxillofacial Fractures in Elderly Patients Compared with Young Patients
}

\author{
Ichiro Ogura, ${ }^{1,2}$ Naohisa Hirahara, ${ }^{1}$ Hirotaka Muraoka, ${ }^{1}$ Taiga Fukuda, ${ }^{1}$ Yoshinobu Hara, ${ }^{1}$ \\ and Satoshi Tokunaga ${ }^{1}$ \\ ${ }^{1}$ Department of Radiology, Nihon University School of Dentistry at Matsudo, Matsudo, Chiba 271-8587, Japan \\ ${ }^{2}$ Radiology, The Nippon Dental University Niigata Hospital, 1-8 Hamaura-cho, Chuo-ku, Niigata, Niigata 951-8580, Japan
}

Article History

Received 16 March 2016

Accepted 2 May 2016

\begin{abstract}
The purpose of this study was to investigate the characteristics of maxillofacial fractures in elderly patients in comparison to young patients. A retrospective study was conducted of 376 patients with maxillofacial fractures who underwent 64 multidetector-row CT (MDCT) procedures. The study patients comprised 81 elderly patients ( $\geq 60$ years) and 295 young patients $(<60$ years). Age, sex, cause of injury and fracture location according to MDCT were analyzed using the $\chi^{2}$ test with Fisher's exact test. The proportion of male vs female of elderly patients was $55.6 \%$ vs $44.4 \%$ and that of young patients was $73.9 \%$ vs $26.1 \%(p=0.002)$. The causes of injury in the elderly patients were falls, traffic accidents, assaults, and sports incidents $(59.3 \%, 32.1 \%, 7.4 \%$, and $1.2 \%$, respectively $(p<0.001))$. The percentages of cases with mandibular angle fractures, condylar fractures, and median fractures were $3.7 \%$ of elderly patients vs $22.4 \%$ of young patients $(p<0.001), 63.0 \%$ of elderly patients vs $44.4 \%$ of young patients $(p=0.004)$, and $16.0 \%$ of elderly patients vs $30.8 \%$ of young patients $(p=0.008)$, respectively. In conclusion, mandibular condylar fractures dominate maxillofacial fractures in the elderly compared with mandibular median and angle fractures.
\end{abstract}

Keywords :

computed tomography,

MDCT, maxillofacial trauma,

fracture, elderly

\section{Introduction}

Maxillofacial fractures in elderly patients are less frequent than young patients and mostly related to age-related changes and systemic pathologic conditions (1-3). However, traumatic injuries in the elderly have been increasing in recent years; this is due to increased active life span with advances in medicine that result in a higher percentage of older people in the population $(4,5)$. Falls are a frequent cause of trauma, especially in the elderly, due to disability, morbidity and increased health care utilization (6-9). The maxillofacial bones support such functions as respiration, sense of smell, vision, speech, and eating (10). Therefore, maxillofacial fractures require accurate radiologic diagnosis and surgical management to prevent severe functional debilitation and cosmetic deform-

\section{Correspondence to :}

Ichiro Ogura

E-mail : ogura@ngt.ndu.ac.jp ity. The fracture morphology of maxillofacial trauma is often complex, requiring the clinician to be familiar with imaging findings.

In recent years, multidetector-row computed tomography (MDCT) with multiplanar reformation (MPR) and three-dimensional (3D) imaging has become a standard part of the assessment of facial injury because of the exquisite sensitivity of this imaging technique for fracture $(11,12)$. MDCT is an effective tool for the detection of maxillofacial fracture location, degree of fragment dislocation, soft tissue edema, and hemorrhage(13-18). Furthermore, trauma encompasses not only ambulatory patients with suspected maxillofacial fractures but also patients with loss of consciousness. In the trauma setting, rapid access to imaging is important to the trauma team in making diagnoses and guiding management decisions. In the acute setting, MDCT is becoming the imaging modality of choice(19). This is one reason for its wide availability at 


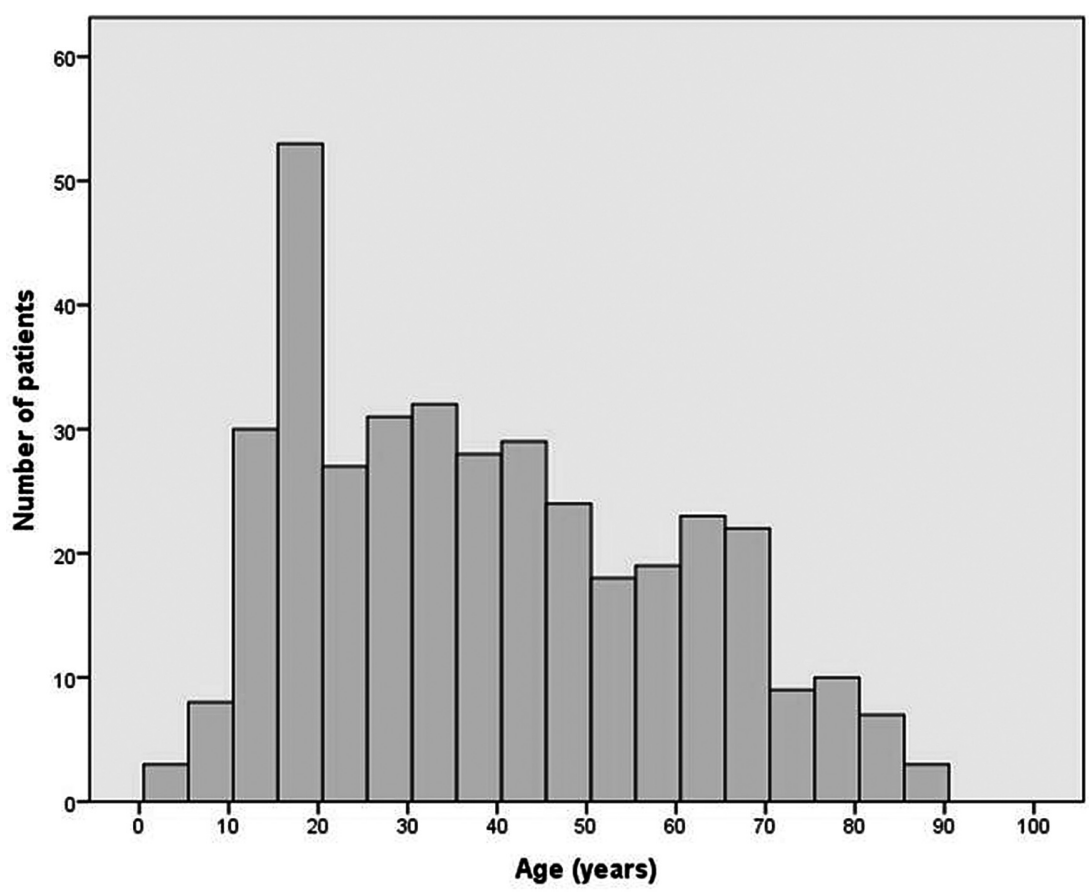

Fig. 1 Distribution of patients with maxillofacial fractures according to age.

most hospitals; another reason is its ability to acquire images rapidly. However, to our knowledge, maxillofacial fractures in the elderly, especially in comparison with young patients, as detected with MDCT have not been previously reported in the literature. The purpose of this study was to analyze the characteristics of maxillofacial fractures in elderly patients compared with young patients.

\section{Materials and Methods}

Patient Population

This retrospective study was approved by the ethics committee of our institution (No. EC 10-039). After obtaining written informed consent, 376 patients (263 men, 113 women; age 3-87 years, mean age 39.2 years) with maxillofacial fractures underwent 64-MDCT within 7 days after injury at our university hospital from April 2006 to May 2014(Fig. 1). The study patients consisted of 81 elderly patients (45 men, 36 women; age 60-87 years, mean age 69.8 years) and 295 young patients ( 218 men, 77 women; age 3-59 years, mean age 30.8 years).

\section{Image acquisition}

CT imaging was performed with a 64-MDCT (Aquilion 64, Toshiba Medical Systems, Otawara, Japan) using the maxillofacial trauma protocol at our hospital: tube voltage, $120 \mathrm{kV}$; tube current, $100 \mathrm{~mA}$; field of view, $240 \mathrm{~mm} \times 240$ $\mathrm{mm}$; rotation time, $1.0 \mathrm{~s}$. The protocol consisted of axial acquisition $(0.50 \mathrm{~mm})$ with axial $(3.0 \mathrm{~mm})$, coronal $(3.0 \mathrm{~mm})$ and sagittal $(3.0 \mathrm{~mm}) \mathrm{MPR}$ and 3D images.

\section{Image analysis}

The MDCT images were independently evaluated by two oral and maxillofacial radiologists, and any discrepancies were resolved by consensus. The maxillofacial fracture locations were classified according to the distribution described by Lieger et al.(20) into eight types: mandibular median, paramedian, angle, condylar, Le Fort (I-III), isolated maxillary, isolated zygomatic arch, and zygomaticomaxillary complex type. The age, sex, cause of injury and fracture location with MDCT were analyzed.

\section{Statistical analysis}

The statistical analysis for the comparison between elderly ( $\geq 60$ years) and young ( $<60$ years) patients was performed using the $\chi^{2}$ test with Fisher's exact test. These analyses were performed with the statistical package IBM SPSS Statistics version 22 (IBM Japan, Tokyo, Japan). A $p^{- \text {value }}<0.05$ was considered statistically significant.

\section{Results}

Table 1 shows the comparison between the elderly and young study patients with maxillofacial fractures. The 
Table 1 Comparison between elderly and young patients with maxillofacial fractures

\begin{tabular}{|c|c|c|c|c|c|}
\hline \multirow[t]{2}{*}{ Parameter } & \multicolumn{4}{|c|}{ Patients with maxillofacial fractures } & \multirow[b]{2}{*}{$P$ value } \\
\hline & Elderl & $\mathrm{y}(\geqq 60$ years $)$ & Young ( $<60$ years) & Total & \\
\hline Number of patients & & $81(21.5 \%)$ & $295(78.5 \%)$ & $376(100 \%)$ & \\
\hline \multicolumn{6}{|l|}{ Age (years) } \\
\hline Mean \pm SD & & $69.8 \pm 7.8$ & $30.8 \pm 13.9$ & $39.2 \pm 20.6$ & \\
\hline Range & & $60-87$ & $3-59$ & $3-87$ & \\
\hline Gender & & & & & 0.002 \\
\hline Male & & $45(55.6 \%)$ & $218(73.9 \%)$ & $263(69.9 \%)$ & \\
\hline Female & & $36(44.4 \%)$ & $77(26.1 \%)$ & $113(30.1 \%)$ & \\
\hline Cause of injury & & & & & $<\mathbf{0 . 0 0 1}$ \\
\hline Fall & & $48(59.3 \%)$ & $120(40.7 \%)$ & $168(44.7 \%)$ & \\
\hline Traffic accident & & $26(32.1 \%)$ & $85(28.8 \%)$ & $111(29.5 \%)$ & \\
\hline Assault & & $6(7.4 \%)$ & $45(15.3 \%)$ & $51(13.6 \%)$ & \\
\hline Sports & & $1(1.2 \%)$ & $45(15.3 \%)$ & $46(12.2 \%)$ & \\
\hline \multicolumn{6}{|l|}{ Fracture location with MDCT } \\
\hline \multicolumn{6}{|l|}{ Mandible } \\
\hline median & & $13(16.0 \%)$ & $91(30.8 \%)$ & $104(27.7 \%)$ & 0.008 \\
\hline paramedian & & $12(14.8 \%)$ & $51(17.8 \%)$ & $63(16.8 \%)$ & 0.737 \\
\hline angle & & $3(3.7 \%)$ & $66(22.4 \%)$ & $69(18.4 \%)$ & $<0.001$ \\
\hline condylar & & $51(63.0 \%)$ & $131(44.4 \%)$ & $182(48.4 \%)$ & 0.004 \\
\hline \multicolumn{6}{|l|}{ Midface } \\
\hline Le Fort I-III & & $2(2.5 \%)$ & $15(5.1 \%)$ & $17(4.5 \%)$ & 0.545 \\
\hline isolated maxillary & & $1(1.2 \%)$ & $17(5.8 \%)$ & $18(4.8 \%)$ & 0.138 \\
\hline isolated zygomatic arch & & $5(6.2 \%)$ & $6(2.0 \%)$ & $11(2.9 \%)$ & 0.064 \\
\hline zygomaticomaxillary co & mplex & $13(16.0 \%)$ & $54(18.3 \%)$ & $67(17.8 \%)$ & 0.744 \\
\hline
\end{tabular}

$\mathrm{SD}$, standard deviation.

MDCT, multidetector CT.

proportion of men vs women was $55.6 \%$ (45 cases) vs $44.4 \%$

(36 cases) among the 81 elderly patients and $73.9 \%$ (218 cases) vs $26.1 \%$ (77 cases) among the 295 young patients, respectively $(p=0.002)$. Regarding cause of injury, the proportions of falls, traffic accidents, assaults, and sports incidents were $59.3 \%$ (48 cases), 32.1\% (26 cases), 7.4\% (6 cases), and $1.2 \%$ ( 1 cases) among the 81 elderly patients, respectively $(p<0.001)$.
The percentages of cases with angle fractures, condylar fractures, and median fractures were $3.7 \%$ (3/81 cases) of elderly patients vs $22.4 \%$ (66/295 cases) of young patients ( $p$ $<0.001), 63.0 \%$ (51/81 cases) of elderly patients vs $44.4 \%$ (131/295 cases) of young patients $(p=0.004)$, and $16.0 \%$ (13/81 cases) of elderly patients vs $30.8 \%$ (91/295 cases) of young patients $(p=0.008)$, respectively. Figures 2 and 3 show mandibular fractures and midface fractures, respec- 

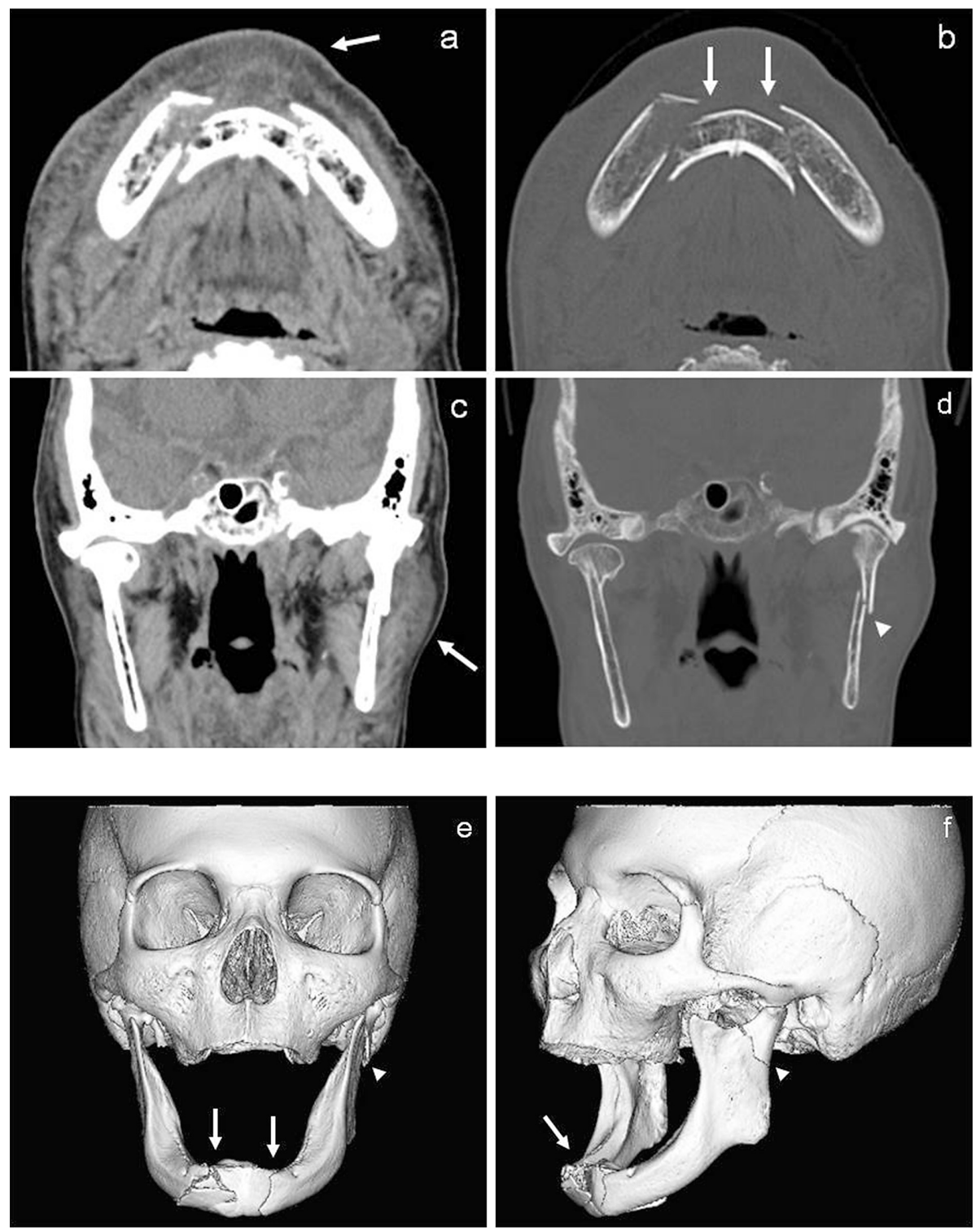

Fig. 2 An 85-year-old women with mandibular fractures resulting from falls. Axial soft-tissue algorithm CT (a) demonstrates median fractures with soft tissue edema (arrow). Axial bone algorithm CT (b) demonstrates median fractures (arrows). Coronal soft-tissue algorithm CT (c)demonstrates a condylar fracture with soft tissue edema(arrow). Coronal bone algorithm CT (d) demonstrates a condylar fracture (arrowhead). Three-dimensional imaging (e, f) shows median fractures (arrows) and condylar fracture (arrowhead) to better advantage.

tively.

\section{Discussion}

Maxillofacial fractures in the elderly occur less frequently than in younger people (1-3). The purpose of this study was to investigate the characteristics of maxillofacial fractures in the elderly, especially in comparison with young patients.

Goldschmidt et al. (1) showed that men sustained 56.1\% of the craniomaxillofacial fractures in the elderly (60 years of age and older) while women sustained 43.9\%. Fasola et al. (3) showed that the male to female ratio was 1.1:1 in patients above 60 years with maxillofacial fractures. On the other hand, Sawazaki et al. (21) indicated a male/female ratio of 3.05:1 and a mean age of 28.4 years among a total of 317 condylar fractures. In the present study, the proportions of men vs women were $55.6 \%$ vs $44.4 \%$ in the elderly group $(\geq$ 60 years) and $73.9 \%$ vs $26.1 \%$ in the young group $(<60$ years), respectively. The incidence of maxillofacial fractures in women was observed to increase in the elderly in the present study. We consider that the age and sex distribution 

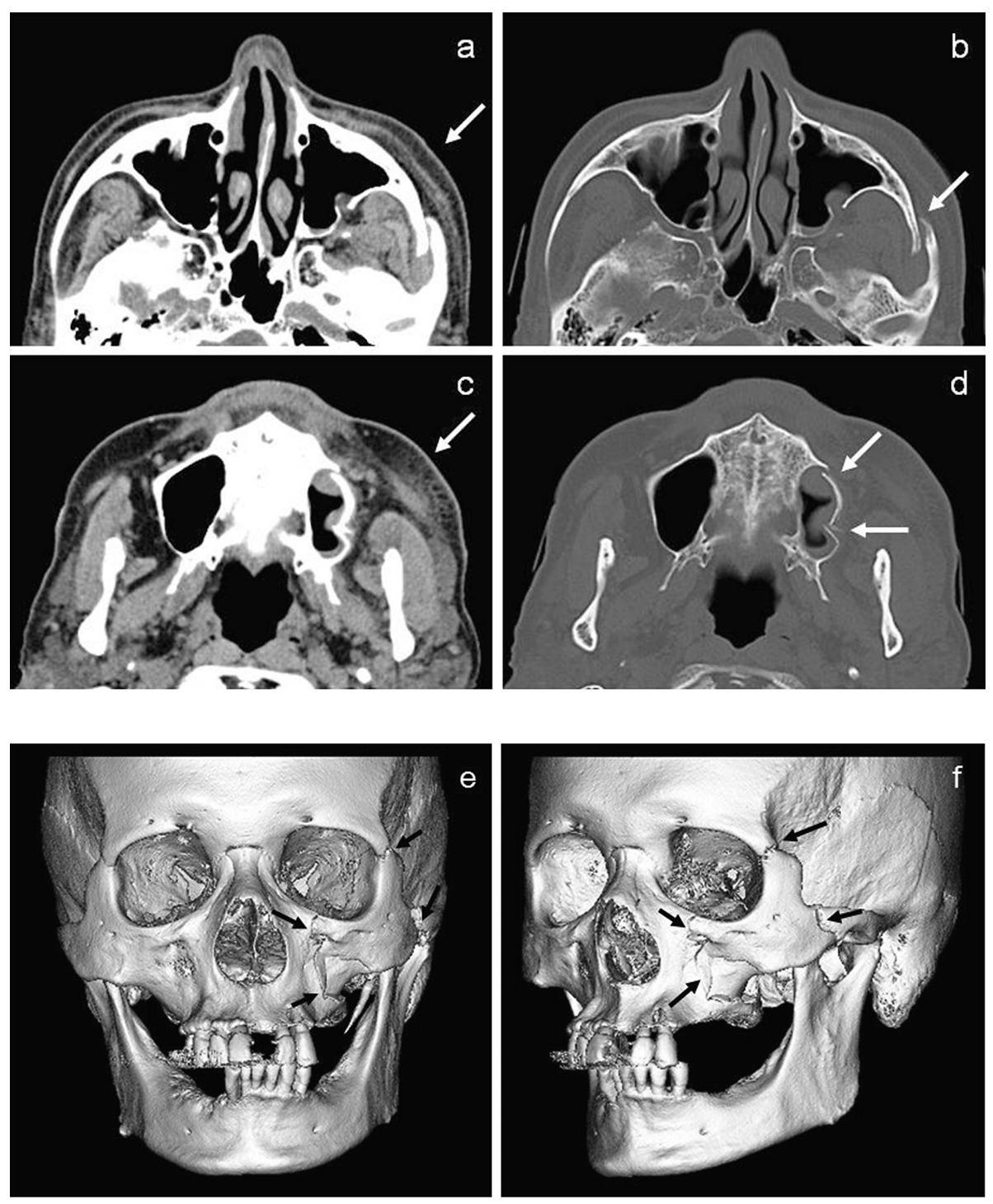

Fig. 3 A 74-year-old man with midface fractures resulting from falls. Axial soft-tissue algorithm CT (a) demonstrates a zygomatic arch fracture with soft tissue edema (arrow). Axial bone algorithm CT (b) demonstrates a zygomatic arch fracture (arrow). Axial soft-tissue algorithm CT(c)demonstrates maxillary fractures with soft tissue edema(arrow). Axial bone algorithm CT (d) demonstrates maxillary fractures (arrows). Three-dimensional imaging (e, f) shows zygomaticomaxillary complex fractures (arrowheads) to better advantage.

is closely related to the circumstances of injury, because the life span is different between men and women.

Velayutham et al. (5) showed that the most common cause of facial injuries among older people was falls, whereas among younger people it was interpersonal violence. Sasaki et al. (22) indicated that $31 \%$ of maxillofacial fractures were due to traffic accidents, $29 \%$ to accidental falls, $23 \%$ to violence and $14 \%$ to sports. The authors found that the percentage of cases with maxillofacial fractures resulting from falls was $59.3 \%$ in the elderly group vs $40.7 \%$ in the young group underwent MDCT at Nihon University School of Dentistry at Matsudo. Therefore, we consider that falls are the most common cause of maxillofacial fracture in the elderly.

Regarding midface fractures, Yamamoto et al. (23) showed that zygomaticomaxillary complex fractures were most frequently involved in falls. Salonen et al. $(6,7)$ reported that the zygomaticomaxillary complex was the most common fracture in facial trauma resulting from falling accidents. The present study indicated that the zygomaticomaxillary 
complex fracture was most frequent among midfacial fractures in the elderly. Injuries to the zygomatic bone or arch usually result from a forceful blow to the cheek or side of the face. We believe that trauma force resulting from falls applied in the facial region causes direct fractures of the zygomaticomaxillary complex.

The present study found that mandibular condylar fracture was most frequent type of maxillofacial fractures in the elderly; the percentage of cases with mandibular condylar fractures was $63.0 \%$ in the elderly group vs $44.4 \%$ in the young group. Salonen et al. $(6,7)$ reported that mandibular condylar fractures were the most frequently occurring type of maxillofacial fractures in falling accidents. Sawazaki et al.(21) reported that mandibular median fractures were significantly associated with both unilateral and bilateral fractures of the mandibular condyle. We believe that trauma force from falling applied to the mandibular median, paramedian and angle regions causes indirect fractures of the mandibular condyle with or without fractures in the mandibular median, paramedian or angle region. Furthermore, among the elderly population, the present study indicated that maxillofacial fractures occurred more frequently in women, and that the percentage of cases with mandibular median fractures and mandibular angle fractures was $16.0 \%$ in the elderly group vs $30.8 \%$ in the young group and $3.7 \%$ in the elderly group vs $22.4 \%$ in the young group, respectively. The mandibular condylar bone in elderly women may be weak because of low bone density, physical status, and systemic disease such as osteoporosis. Therefore, we believe that the incidence of mandibular condylar fractures is the highest among the types of maxillofacial fractures in the elderly.

The limitation of the present study was that it did not analyze the relationship between medical conditions and maxillofacial fractures in the elderly. Velayutham et al.(5) reported coexisting medical conditions and polypharmacy in elderly patients with maxillofacial trauma, and observed that cardiovascular disease was the most frequent, followed by musculoskeletal disease including osteoporosis. Therefore, we believe that the relationship between medical conditions and maxillofacial fractures in the elderly is an important topic for future studies.

\section{Conclusions}

The present study showed that the percentage of cases with mandibular angle fractures, condylar fractures, and median fractures was $3.7 \%$ in the elderly vs $22.4 \%$ in young patients, $63.0 \%$ in the elderly vs $44.4 \%$ in young patients, and $16.0 \%$ in the elderly vs $30.8 \%$ in young patients, respectively. Mandibular condylar fractures dominate maxillofacial fractures in the elderly compared with mandibular median and angle fractures.

\section{Acknowledgments}

For providing guidance from beginning to end, I am deeply grateful to Professor T. Kaneda from the Department of Radiology at the Nihon University School of Dentistry at Matsudo. Further, the author would like to acknowledge the generous, multifaceted cooperation of everyone in the Nihon University School of Dentistry at Matsudo.

Conflict of interest: All authors declare that they have no conflict of interest.

\section{References}

1. Goldschmidt MJ, Castiglione CL, Assael LA, Litt MD: Craniomaxillofacial trauma in the elderly. J Oral Maxillofac Surg, 53: 1145-1149, 1995.

2. Gerbino G, Roccia F, De Gioanni PP, Berrone S: Maxillofacial trauma in the elderly. J Oral Maxillofac Surg, 57: 777-783, 1999.

3. Fasola AO, Obiechina AE, Arotiba JT: Incidence and pattern of maxillofacial fractures in the elderly. Int J Oral Maxillofac Surg, 32: 206-208, 2003.

4. Yamamoto K, Matsusue Y, Murakami K, Horita S, Sugiura T, Kirita T: Maxillofacial fractures in older patients. J Oral Maxillofac Surg, 69: 2204-2210, 2011.

5. Velayutham L, Sivanandarajasingam A, O'Meara C, Hyam D: Elderly patients with maxillofacial trauma: the effect of an ageing population on a maxillofacial unit's workload. Br J Oral Maxillofac Surg, 51: 128-132, 2013.

6. Salonen EM, Koivikko MP, Koskinen SK: Multidetector computed tomography imaging of facial trauma in accidental falls from heights. Acta Radiol, 48: 449-455, 2007.

7. Salonen EM, Koivikko MP, Koskinen SK: Acute facial trauma in falling accidents: MDCT analysis of 500 patients. Emerg Radiol, 15: 241-247, 2008.

8. Ohki T, Ogura I: Characteristic multidetector computed tomography findings of maxillofacial fractures resulting from falls in the elderly. Int J Oral-Med Sci, 13: 1-5, 2014.

9. Honda I, Ogura I: Characteristic multidetector CT findings of mandibular fractures: comparison with falls and violence. Int J Oral-Med Sci, 13: 53-58, 2014.

10. Smith HL, Chrischilles E, Janus TJ, Sidwell RA, Ramirez M, 
Peek-Asa C, Sahr SM: Clinical indicators of midface fracture in patients with trauma. Dent Traumatol, 29: 313-318, 2013.

11. Chu ZG, Yang ZG, Dong ZH, Chen TW, Zhu ZY, Deng W, Xiao $\mathrm{JH}$ : Features of cranio-maxillofacial trauma in the massive Sichuan earthquake: analysis of 221 cases with multi-detector row CT. J Craniomaxillofac Surg, 39: 503-508, 2011.

12. Patel R, Reid RR, Poon CS: Multidetector computed tomography of maxillofacial fractures: the key to high-impact radiological reporting. Semin Ultrasound CT MR, 33: 410-417, 2012.

13. Ogura I, Kaneda T, Mori S, Sekiya K, Ogawa H, Tsukioka T: Characterization of mandibular fractures using 64-slice multidetector CT. Dentomaxillofac Radiol, 41: 392-395, 2012.

14. Ogura I, Sasaki Y, Kaneda T: Analysis of mandibular condylar and glenoid fossa fractures with computed tomography. Eur Radiol, 24: 902-906, 2014.

15. Ogura I, Sasaki Y, Kaneda T: Multidetector computed tomography of maxillofacial fractures. Jpn Dent Sci Rev, 50: 86-90, 2014

16. Ogura I, Kawashima Y, Muramatsu T, Ito K, Kaneda T: Characteristic computed tomographic findings of midface fractures relative to the cause of injury: a fall or violence. Oral Radiol, 31: 149-154, 2015.

17. Ogura I, Kaneda T, Sasaki Y, Buch K, Sakai O: Prevalence of temporal bone fractures in patients with mandibular fractures using multidetector-row CT. Clin Neuroradiol, 25: 137-141, 2015.

18. Ogura I, Hara Y, Tokunaga S, Kaneda T: Mandibular coronoid process fractures: prevalence and characteristic multidetector CT findings. Oral Sci Int, 2016.

19. Sung EK, Nadgir RN, Sakai O: Computed tomographic imaging in head and neck trauma: what the radiologist needs to know. Semin Roentgenol, 47: 320-329, 2012.

20. Lieger O, Zix J, Kruse A, Iizuka T: Dental injuries in association with facial fractures. J Oral Maxillofac Surg, 67: 1680-1684, 2009.

21. Sawazaki R, Lima Júnior SM, Asprino L, Moreira RWF, de Moraes M: Incidence and patterns of mandibular condyle fractures. J Oral Maxillofac Surg, 68: 1252-1259, 2010.

22. Sasaki R, Ogiuchi H, Kumasaka A, Ando T, Nakamura K, Ueki T, Okada Y, Asanami S, Chigono Y, Ichinokawa Y, Satomi T, Matsuo A, Chiba H: Analysis of the pattern of maxillofacial fracture by five departments in Tokyo: a review of 674 cases. Oral Sci Int, 6: 1-7, 2009.

23. Yamamoto K, Kuraki M, Kurihara M, Matsusue Y, Murakami K, Horita S, Sugiura T, Kirita T: Maxillofacial fractures resulting from falls. J Oral Maxillofac Surg, 68: 1602-1607, 2010. 